\title{
Perancangan Pengendali dengan Umpan Balik Keadaan untuk Networked Control Systems
}

\author{
Jurusan Teknik Elektro \\ Universitas Jenderal Achmad Yani, Cimahi, 40533 \\ Telp/Fax : (022) 6642063 \\ E-mail : asepnajmu@yahoo.com
}

Asep Najmurrokhman, Yuda Bakti Zainal, Sunubroto, Safreni Candra Sari

\begin{abstract}
Abstrak
Makalah ini menguraikan tentang perancangan pengendali dengan umpan balik keadaan untuk Networked Control Systems (NCS). Perkembangan teknologi informasi yang dipicu karena majunya teknologi elektronika dan informatika memberi dorongan bagi peneliti sistem kendali untuk melibatkan jaringan komunikasi sebagai bagian dari loop kendali. Komunitas sistem kendali menamakan istilah untuk sistem tersebut sebagai Networked Control Systems (NCS). Dalam NCS, komponen-komponen penyusun sistem terpisah secara spasial dan dihubungkan dengan jaringan komunikasi. Implementasi NCS dipandang menguntungkan karena berkurangnya biaya instalasi, kemudahan dalam pemeliharaan, mudah dikonfigurasi ulang, dan sebagainya. Namun, masuknya jaringan komunikasi dalam lingkar kendali menambah kompleksitas dalam analisis dan sintesis pengendalinya, karena adanya parameter yang dipunyai oleh jaringan komunikasi seperti adanya waktu tunda transmisi (time delay), kemungkinan hilangnya paket data yang dikirimkan (packet loss), dan keterbatasan lebar pita dan kecepatan transmisi data. Beberapa parameter dalam jaringan tersebut bisa menyebabkan penurunan performansi dalam sistem, bahkan mungkin menyebabkan ketidakstabilan. Oleh karena itu, salah satu tujuan penelitian dalam NCS adalah merancang pengendali yang mampu menangani parameter tersebut sehingga lingkar tertutup NCS bersifat stabil dan mencapai performansi tertentu.
\end{abstract}

Makalah ini menguraikan tentang perancangan pengendali dengan umpan balik keadaan untuk NCS sehingga lingkar tertutupnya bersifat stabil. Pemodelan sistemnya didekati dengan Markovian Jump Systems (MJS) yang mengakomodasi sifat stokastik dari parameter jaringan. Skema formulasi untuk analisis dan perancangannya dilakukan melalui pertidaksamaan matriks linier. Hasil utama dari penelitian yang dipaparkan dalam makalah ini adalah formulasi pertidaksamaan matriks linier agar NCS lingkar tertutup dengan umpan balik keadaan bersifat stabil. Sebuah simulasi numerik diberikan untuk memperlihatkan keefektifan dari perancangan yang diuraikan dalam makalah ini.

\section{Keywords}

Networked Control Systems, Markovian Jump Systems, Umpan Balik Keadaan, Pertidaksamaan Matriks Linier

\section{PENDAHULUAN}

Networked Control Systems (NCS) adalah sistem kendali yang melibatkan jaringan komunikasi sebagai bagian dari lingkar kendali [1]. Penggunaan jaringan komunikasi menawarkan keuntungan yang cukup signifikan dalam hal keandalan, penggunaan sumber daya, pemeliharaan, diagnosa sistem apabila terjadi kesalahan, dan sebagainya [2]. Aplikasi NCS dapat ditemukan pada kendaraaan yang menerapkan kendali otomatis, robotika, pesawat udara nirawak (unmanned aerial vehicle), jaringan sensor nirkabel, dan sebagainya [3]. Disamping keuntungan yang ditawarkan, ada beberapa parameter yang muncul dalam jaringan komunikasi seperti waktu tunda transmisi dan kemungkinan hilangnya data saat transmisi yang bisa menyebabkan penurunan kinerja sistem dan bahkan bisa menyebabkan ketidakstabilan [2]. Heemels, dkk. [4] menyimpulkan beberapa parameter jaringan yang harus dipertimbangkan meliputi waktu tunda transmisi data yang bervariasi, adanya kemungkinan data hilang (yang disebut packet dropout) di tengah jalan akibat ketidakhandalan jaringan, adanya error kuantisasi disebabkan keterbatasan panjang kata (finite word length), 
interval pencacahan yang berubah-ubah secara acak, dan penggunaan bersama jaringan oleh beberapa komponen (multi nodes). Secara ringkas, efek jaringan komunikasi dalam NCS diperlihatkan dalam Gambar 1.
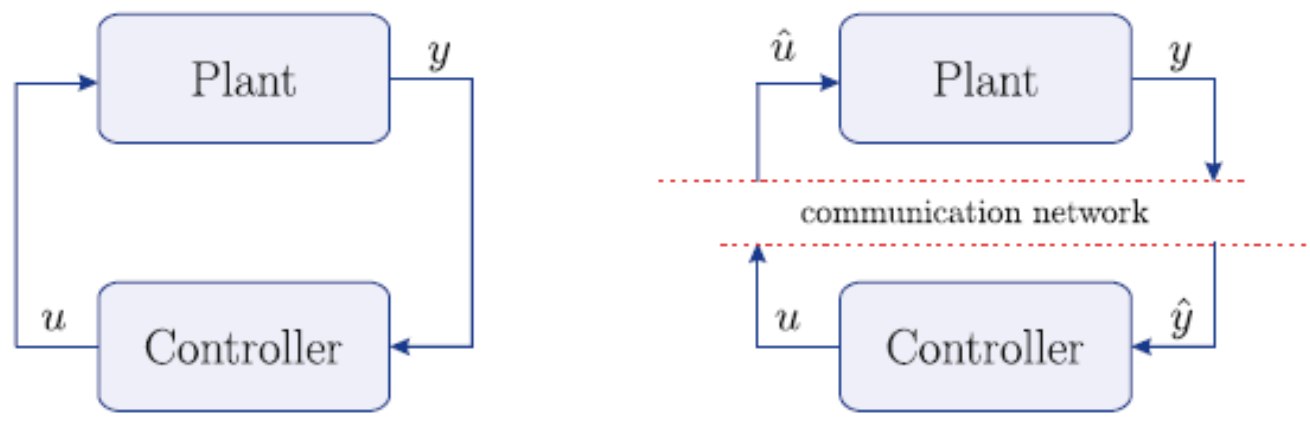

Gambar 1. Efek jaringan komunikasi pada NCS [5]

Berdasarkan gambar 1, adanya parameter jaringan menyebabkan sinyal output $y$ dari plant yang dikirim ke pengendali tidak sama lagi, mungkin terlambat (delay) atau bahkan tidak sampai ke tujuan (packet dropout). Demikian pula sinyal kendali $u$ yang dihasilkan oleh pengendali untuk dikirim ke aktuator akan sangat tergantung kepada parameter jaringan. Para peneliti NCS membagi dua kategori untuk parameter jaringan tersebut. Ada yang menganggap bahwa nilainya tertentu (deterministik) dan berada dalam satu rentang nilai (bound), sementara yang lain mempertimbangkan sifat acak (stokastik) dari parameter tersebut. Dalam hal sifat stokastik yang dipertimbangkan, umumnya peneliti memodelkan sistemnya dengan pendekatan Markov Jump System (MJS) artinya sistem tersusun oleh subsistem yang masing-masing tergantung dari status rantai Markov untuk sistem tersebut. Sistem seolah-olah lompat (jump) dari satu subsistem ke subsistem lain. Dalam pemodelannya, ada nilai probabilitas transisi dari satu status (yang biasanya disebut dengan mode sistem) ke mode lainnya.

\section{NETWORKED CONTROL SYSTEMS}

Secara sederhana, diagram blok NCS diilustrasikan pada gambar 2. Sinyal $u, w, y$, dan $z$ berturut-turut menandai sinyal pengendali, masukan luar, sinyal keluaran yang terukur, dan sinyal keluaran yang dikendalikan. Sinyal $y$ adalah data pengukuran yang dilakukan oleh sensor, sedangkan sinyal $u$ adalah sinyal kendali dihitung oleh pengendali dan diberikan kepada aktuator.

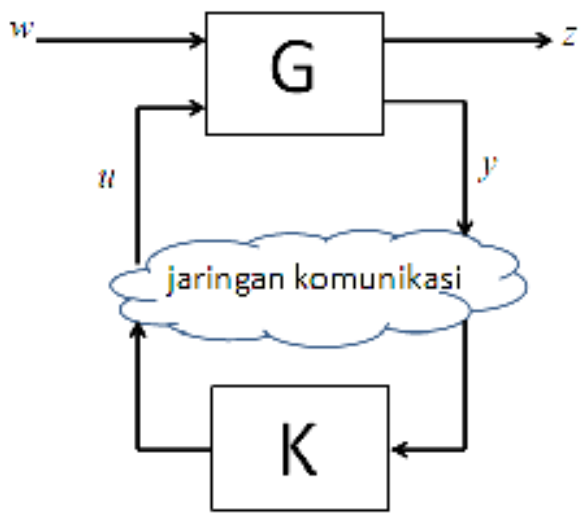

Gambar 2. Diagram blok NCS [6]

Pemodelan NCS mengasumsikan beberapa hal berikut [7]:

(a) sensor bekerja dengan prinsip time-driven, artinya data sinyal keluaran diambil secara periodik,

(b) pengendali bekerja dengan prinsip event-driven, artinya sinyal kendali dihitung sesaat setelah data sensor diterima,

(c) aktuator bekerja dengan prinsip event-driven, artinya sinyal kendali diberikan kepada aktuator setelah data baru dari pengendali diterima oleh aktuator. 
Diagram waktu spesifik yang menggambarkan mekanisme kerja dari sensor, pengendali, dan aktuator dalam NCS dilukiskan pada gambar 3 [8]. Perhatikan bahwa adanya waktu tunda transmisi data dari sensor ke pengendali $\left(\tau_{\mathrm{i}}^{\mathrm{s}}\right)$ dan dari pengendali ke aktuator $\left(\tau_{\mathrm{i}}^{\mathrm{a}}\right)$ menyebabkan sinyal yang dikirimkan ke plant terlambat sebesar $\tau_{\mathrm{i}}^{\mathrm{s}}+\tau_{\mathrm{i}}^{\mathrm{a}}$. Keterlambatan respon sinyal kendali akan lebih lama apabila terjadi kehilangan paket data selama transmisi (packet dropout).

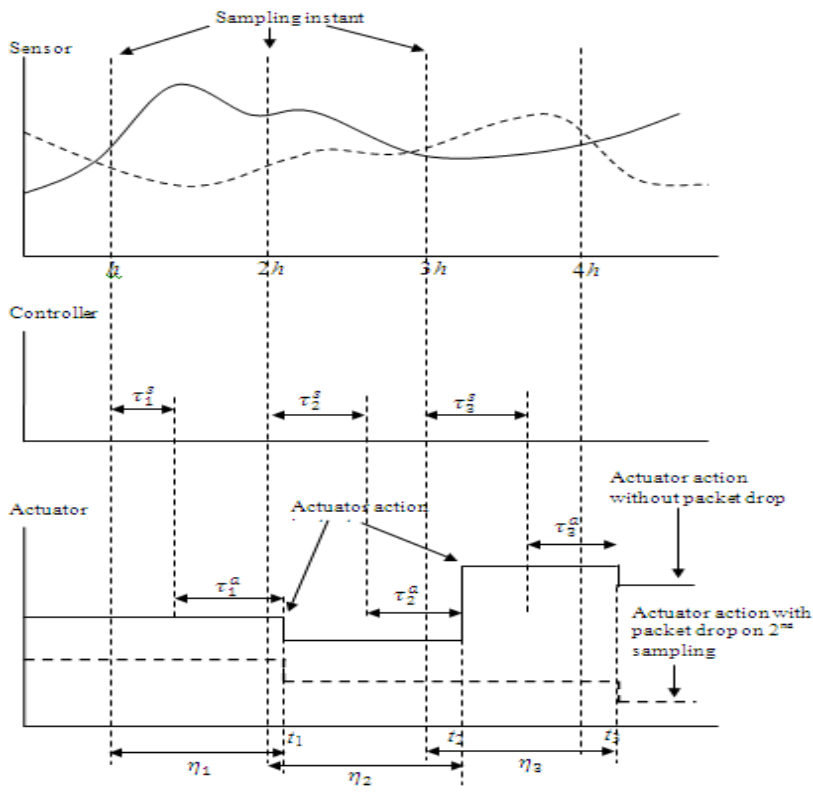

Gambar 3. Diagram waktu NCS [8]

\section{PEMODELAN NCS DENGAN MARKOV JUMP SYSTEMS}

Satu isu penting dalam sistem kendali adalah kemampuan mempertahankan perilaku sistem yang diinginkan dan pemenuhan kualifikasi kinerja sistem dalam kondisi apapun termasuk perubahan mendadak dalam dinamika sistemnya. Perubahan tersebut dapat terjadi misalnya akibat gangguan tiba-tiba dari luar, perubahan interkoneksi subsistem, atau perubahan sesaat titik operasi plant. Model Markov Jump Systems (MJS) mengakomodasi perubahan tersebut dalam pemodelan dinamika sistemnya. Untuk memberi ilustrasi terhadap situasi tersebut, misal sebuah dinamika sistem dinyatakan dengan model $\mathrm{G}_{1}$. Dengan adanya perubahan tiba-tiba, model sistemnya berubah menjadi $G_{2}$. Secara umum, misalnya sistem tersebut mengalami serangkaian perubahan yang menggeser atau melompat (jump) dari satu model ke model lain, maka kondisi tersebut bisa diasosiasikan dengan perubahan mode operasi sistem tersebut atau sistem tersebut bertransisi dari satu mode ke mode lainnya. Dalam NCS, mode operasi sistemnya bergantung kepada parameter jaringan komunikasi, seperti waktu tunda transmisi data, kemungkinan hilangnya paket data yang dikirim (packet dropout), dan sebagainya. Dengan demikian, sebuah NCS yang dimodelkan dengan MJS memiliki matriks-matriks sistem yang nilainya bergantung kepada parameter. Ishii [9] menggambarkan NCS yang bergantung kepada salah satu parameter jaringan yaitu adanya paket data yang hilang seperti diperlihatkan pada gambar 4. 


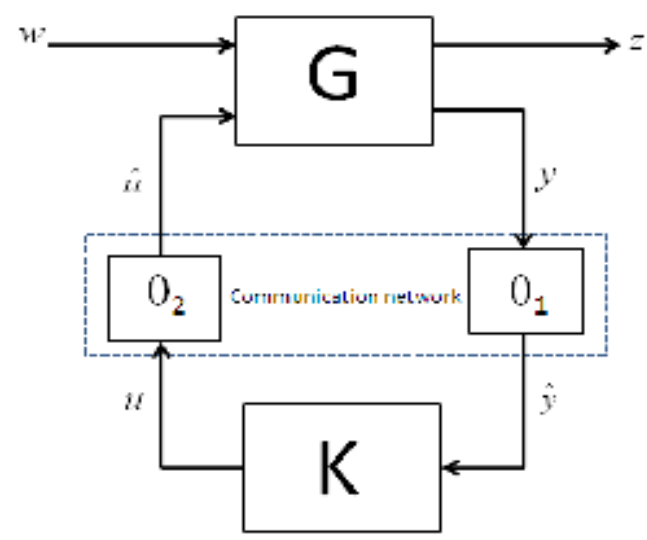

Gambar 4. NCS dengan parameter jaringan $\theta_{i}$

Pada gambar 4, $\theta_{1}$ menandai parameter jaringan untuk pengiriman data dari sensor ke pengendali, sedangkan $\theta_{2}$ menandai parameter jaringan untuk pengiriman data dari pengendali ke aktuator. Salahsatu bentuk pemilihan state pada rantai Markov-nya didasarkan pada kondisi apakah data yang ditransmisikan sempurna atau ada yang hilang. Dengan parameter tersebut, statenya dapat dituliskan dalam bentuk berikut:

$$
\theta_{i}=\left\{\begin{array}{l}
0, \text { terjadi packet dropout } \\
1, \text { seluruh paket diterima }
\end{array}\right.
$$

Selanjutnya model NCS yang diperoleh berbentuk persamaan ruang keadaan dengan matriks-matriksnya bergantung kepada parameter $\theta_{\mathrm{i}}$ tersebut.

Secara umum, persamaan ruang keadaan NCS dalam bentuk waktu kontinyu dengan state rantai Markov $\theta$ diberikan oleh persamaan berikut:

$$
G:\left\{\begin{array}{c}
\&=A_{\theta(t)} x(t)+B_{\theta(t)} u(t)+G_{\theta(t)} w(t) \\
y(t)=L_{\theta(t)} x(t)+H_{\theta(t)} w(t) \\
z(t)=C_{\theta(t)} x(t)+D_{\theta(t)} u(t) \\
x(0)=x_{0}, \theta(0)=\theta_{0}
\end{array}\right.
$$

dengan $x(t)$ menyatakan variabel state sistem, $u(t)$ adalah input kendali, $w(t)$ menandai deretan derau (noise) yang masuk ke dalam sistem, $y(t)$ adalah variabel output terukur yang disediakan untuk pengendali, dan $z(t)$ menyatakan output sistem. Matriks-matriks sistemnya bergantung kepada state dari rantai Markov $\theta(t)$ yang nilainya berada dalam himpunan berhingga $\boldsymbol{\aleph} \equiv\{1, \ldots, N\}$. Distribusi awal $\theta_{0}$ ditandai dengan $v=\left\{v_{1}, \ldots\right.$, $\left.v_{N}\right\}$ dan matriks probabilitas transisinya ditandai dengan $\mathbf{P}=\left[p_{i j}\right]$. Dengan demikian, mode sistemnya direpresentasikan oleh state $\theta(t)$. Analisis dan perancangan sistem dengan model MJS ini mengeksplorasi sifat-sifat stokastik dari state tersebut. Beberapa hasil analisis stabilitas untuk sistem MJS bisa dibaca misalnya dalam $[10,11]$.

Dalam konteks penelitian yang dilaporkan dalam makalah ini, model NCS dengan MJS dituliskan dalam bentuk berikut:

$$
G:\left\{\begin{array}{c}
\&=A_{\theta(t)} x(t)+B_{\theta(t)} u(t) \\
x(0)=x_{0}, \theta(0)=\theta_{0}
\end{array}\right.
$$

dengan $x(t) \in \mathrm{R}^{\mathrm{n}}, x_{0} \in \mathrm{R}^{\mathrm{n}}, u(t) \in \mathrm{R}^{\mathrm{m}}$, dan $\theta(t) \in \mathcal{N}$ seperti yang disebutkan pada bagian sebelumnya. Proses Markov $\{\theta(t), t \geq 0\}$ selain berada dalam suatu himpunan berhingga $\aleph$ juga menjelaskan perpindahan (jump) antara mode yang berbeda. Probabilitas transisi dari satu mode ke mode lainnya diberikan dalam bentuk berikut:

$$
p_{i j}=\operatorname{Prob}\{\theta(\mathrm{t}+\mathrm{h})=j \mid \theta(t)=i\}=\left\{\begin{array}{c}
\lambda_{i j} h+o(h) \\
1+\lambda_{i i} h+o(h)
\end{array}\right.
$$


Parameter $\lambda_{i j}$ menyatakan laju transisi dari mode $i$ ke mode $j$ dengan $\lambda_{i j} \geq 0$ saat $i \neq j$ dan $\lambda_{i i}=-\sum_{j=1, i \neq j}^{N} \lambda_{i j}$ serta $o(h)$ menandai suku orde tinggi yang memenuhi $\lim _{h \rightarrow 0} \frac{o(h)}{h}=0$. Boukas [12] menurunkan kondisi kestabilan untuk sistem tanpa input $(u(t)=0)$ dalam teorema berikut.

Teorema 1. Sebuah sistem (4) tanpa input bersifat stabil apabila terdapat matriks-matriks simetrik definit positif $P_{i}$ yang memenuhi pertidaksamaan matriks linier berikut:

$$
A_{i}^{T} P_{i}+P_{i} A_{i}+\sum_{j \neq i} \lambda_{i j} P_{j}<0, \forall i \in \mathfrak{\aleph}
$$

\section{PERANCANGAN PENGENDALI UMPAN BALIK}

Ada tiga pendekatan yang dilakukan dalam merancang pengendali umpan balik, yaitu umpan balik keadaan (state feedback), umpan balik output statis (static output feedback), dan umpan balik output dinamis (dynamic output feedback). Perancangan umpan balik yang pertama mengasumsikan bahwa informasi semua variabel keadaan dapat diperoleh secara langsung. Dengan demikian, perancang mengetahui secara eksak tentang variabel keadaaan tersebut. Sementara itu, pendekatan kedua dan ketiga dilakukan apabila perancang hanya memanfaatkan data sensor yang mendeteksi sinyal keluaran dari subsistem yang dikendalikan. Perbedaan antara tipe umpan balik statis dan dinamis terletak pada representasi dinamika pengendalinya. Sebuah pengendali umpan balik keluaran disebut statis apabila perancang harus menemukan gain yang sesuai dengan tujuan pengendaliannya, yang lainnya disebut dinamis apabila representasi ruang keadaan dari pengendalinya diketahui secara lengkap.

Dalam makalah ini, pengendali yang dirancang bertipe umpan balik keadaan dan berbentuk

$$
u(t)=K(\theta(t)) x(t)
$$

dengan $K(\theta(t)$ ) adalah penguatan (gain) dengan dimensi yang sesuai dan nilainya bergantung kepada parameter $\theta(t)$. Berdasarkan persamaan (7), sinyal kendali yang dirancang akan bergantung kepada mode sistem, sehingga nilai $K$ yang dicari sebanyak mode yang ada dalam sistem tersebut. Dengan demikian, apabila saat mode $i$ sinyal pengendalinya menggunakan nilai penguatan $\mathrm{K}(i)$, maka saat mode $j$ sinyal pengendalinya akan melompat dengan nilai penguatan $\mathrm{K}(j)$. Dari kondisi tersebut, terlihat bahwa implementasi NCS dengan pemodelan MJS mensyaratkan informasi yang tersedia meliputi data sensor dan data parameter jaringan.

Substitusi persamaan (7) ke persamaan (4) menghasilkan persamaan sistem lingkar tertutupnya berbentuk:

$$
G K:\left\{\begin{array}{c}
\&=\left(A_{\theta(t)}+B_{\theta(t)} K_{\theta(t)}\right) x(t) \\
x(0)=x_{0}, \theta(0)=\theta_{0}
\end{array}\right.
$$

Dengan menggunakan teorema 1, kestabilan sistem lingkar tertutup dijamin apabila terdapat matriks simetrik definit positif $P_{i}$ yang memenuhi pertidaksamaan matriks berikut:

$$
\left(A_{i}+B_{i} K_{i}\right)^{T} P_{i}+P_{i}\left(A_{i}+B_{i} K_{i}\right)+\sum_{j \neq i} \lambda_{i j} P_{j}<0, \forall i \in \mathfrak{\aleph}
$$

Pertidaksamaan matriks (9) berbentuk nonlinier dalam $P_{i}$ dan $K_{i}$. Supaya pertidaksamaan matriks (9) dapat diubah menjadi pertidaksamaan matriks linier dan kemudian bisa diselesaikan dengan perangkat lunak standar seperti MATLAB [13], maka dilakukan prosedur sebagai berikut:

- Buat matriks baru $X_{i}=P_{i}^{-1}$

- Kalikan $X_{i}$ dengan pertidaksamaan (9) dari arah sebelah kiri dan kanan, sehingga diperoleh pertidaksamaan di bawah ini

$$
X_{i}\left[\left(A_{i}+B_{i} K_{i}\right)^{T} P_{i}+P_{i}\left(A_{i}+B_{i} K_{i}\right)\right] X_{i}+X_{i}\left[\sum_{j \neq i} \lambda_{i j} X_{j}^{-1}\right] X_{i}<0, \forall i \in \aleph
$$

yang dapat dituliskan dalam bentuk lain berikut 


$$
X_{i} A_{i}^{T}+X_{i} K_{i}^{T} B_{i}^{T}+A_{i} X_{i}+B_{i} K_{i} X_{i}+X_{i}\left[\sum_{j \neq i} \lambda_{i j} X_{j}^{-1}\right] X_{i}<0, \forall i \in \mathfrak{\aleph}
$$

- Definisikan matriks-matriks berikut

$$
\begin{aligned}
& S_{i}(X)=\left[\sqrt{\lambda_{i 1}} X_{i}, \mathrm{~L}, \sqrt{\lambda_{i i-1}} X_{i}, \sqrt{\lambda_{i i+1}} X_{i}, \mathrm{~L} \sqrt{\lambda_{i N}} X_{i}\right], \forall i \in \aleph \\
& M_{i}(X)=\operatorname{diag}\left[X_{1}, \mathrm{~L} X_{i-1}, X_{i+1}, \mathrm{~L}, X_{N}\right]
\end{aligned}
$$

sehingga suku $X_{i}\left[\sum_{j \neq i} \lambda_{i j} X_{j}^{-1}\right] X_{i}$ dapat dituliskan menjadi

$$
X_{i}\left[\sum_{j \neq i} \lambda_{i j} X_{j}^{-1}\right] X_{i}=\lambda_{i i} X_{i}+S_{i}(X) M_{i}^{-1}(X) S_{i}^{T}(X)
$$

- Buat matriks baru $Y_{i}=K_{i} X_{i}$ sehingga diperoleh pertidaksamaan matriks linier

$$
X_{i} A_{i}^{T}+Y_{i}^{T} B_{i}^{T}+A_{i} X_{i}+B_{i} Y_{i}+\lambda_{i i} X_{i}+S_{i}(X) M_{i}^{-1}(X) S_{i}^{T}(X)<0
$$

Dengan menggunakan teknik komplemen Schur [14], pertidaksamaan matriks linier terakhir dapat dituliskan dalam bentuk kompak berikut:

$$
\left[\begin{array}{cc}
J_{i} & S_{i}(X) \\
S_{i}^{T}(X) & -M_{i}(X)
\end{array}\right]<0
$$

dengan $J_{i}=X_{i} A_{i}^{T}+Y_{i}^{T} B_{i}^{T}+A_{i} X_{i}+B_{i} Y_{i}+\lambda_{i i} X_{i}$

Teorema berikut merangkum persoalan mencari perancang umpan balik keadaan melalui skema pertidaksamaan matriks linier.

Teorema 2. Sebuah pengendali dengan umpan balik keadaan dalam bentuk (7) bersifat menstabilkan sistem lingkar tertutup (4) apabila terdapat matriks-matriks simetrik definit positif $X_{i}$ dan $Y_{i}$ sebagai solusi dari pertidaksamaan matriks linier (10).

Dari uraian di atas, sebuah pengendali dengan umpan balik keadaan (7) yang menstabilkan sistem (4) dengan probabilitas transisi (5) dapat dicari dengan algoritma berikut:

- Diberikan matriks-matriks sistem $A_{i}, B_{i}$ dan probabilitas transisi $\lambda_{i j}$

- Susun pertidaksamaan matriks linier (10)

- Pecahkan pertidaksamaan matriks linier (10) untuk mendapatkan matriks-matriks $X_{i}$ dan $Y_{i}$

- Bentuk matriks pengendali mengikuti persamaan $K_{i}=Y_{i} X_{i}^{-1}$

Untuk memperlihatkan keefektifan dari algoritma perancangan tersebut, pada bagian ini diberikan sebuah contoh kasus sebuah sistem yang memiliki dua mode dalam realisasinya. Matriks sistemnya dinyatakan sebagai berikut:

$$
\begin{gathered}
A_{1}=\left[\begin{array}{cc}
1 & -0,5 \\
0,1 & 1
\end{array}\right] ; \quad B_{1}=\left[\begin{array}{ll}
1 & 0 \\
0 & 1
\end{array}\right] \\
A_{2}=\left[\begin{array}{cc}
-0,2 & -0,5 \\
0,5 & -0,25
\end{array}\right] ; \quad B_{2}=\left[\begin{array}{ll}
1 & 0 \\
0 & 1
\end{array}\right]
\end{gathered}
$$

dengan probabilitas transisi antar mode tersebut diberikan oleh matriks berikut:

$$
\left[\begin{array}{ll}
\lambda_{11} & \lambda_{12} \\
\lambda_{21} & \lambda_{22}
\end{array}\right]=\left[\begin{array}{cc}
-2,0 & 2,0 \\
3,0 & -3,0
\end{array}\right]
$$

Dua mode tersebut mendeskripsikan kondisi yang mungkin terjadi dalam NCS, misalnya mode satu merefleksikan terjadinya kehilangan data (packet dropout) saat transmisi data, sementara mode kedua 
menggambarkan transmisi data yang sempurna saat data dikirim melalui jaringan. Respon lingkar terbuka (tanpa sinyal kendali) untuk mode satu dan mode dua diperlihatkan pada gambar 5. Terlihat bahwa untuk mode satu sistemnya menjadi tidak stabil, sehingga sistem secara keseluruhan bersifat tidak stabil. Dengan demikian, pengendali yang dirancang harus mampu menstabilkan sistem keseluruhan.

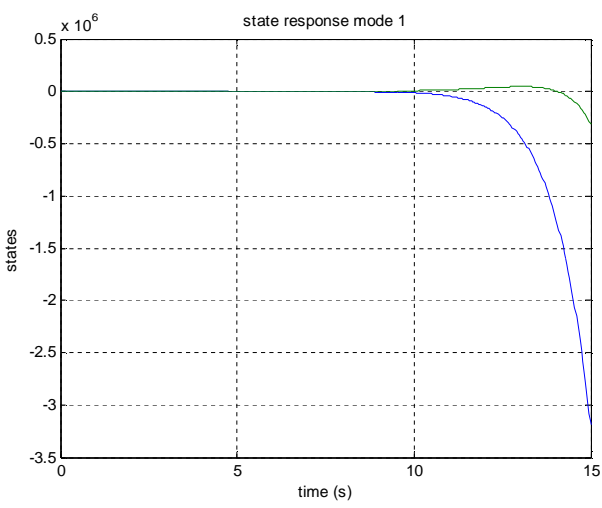

(a)

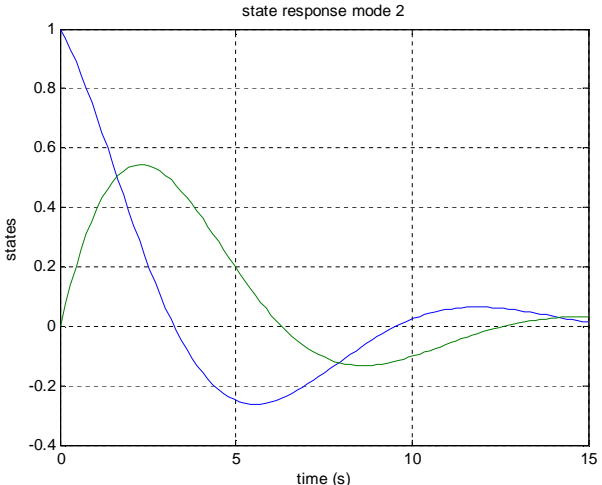

(b)

Gambar 5. Respon keadaan lingkar terbuka untuk mode satu (a) dan mode dua (b)

Dengan menerapkan algoritma pencarian matriks pengendali diperoleh solusi pertidaksamaan matriks linier (10) berikut:

$$
\begin{array}{cc}
X_{1}=\left[\begin{array}{cc}
0,3408 & 0 \\
0 & 0,3408
\end{array}\right] ; \quad X_{2}=\left[\begin{array}{cc}
0,2556 & 0 \\
0 & 0,2556
\end{array}\right] \\
Y_{1}=\left[\begin{array}{cc}
-0,5112 & 0,0059 \\
0,1304 & -0,5112
\end{array}\right] ; \quad Y_{2}=\left[\begin{array}{cc}
-0,0767 & 0 \\
0 & -0,0639
\end{array}\right]
\end{array}
$$

sehingga matriks-matriks pengendalinya berbentuk:

$$
K_{1}=\left[\begin{array}{cc}
-1,5 & 0,0174 \\
0,3826 & -1,5
\end{array}\right] ; \quad K_{2}=\left[\begin{array}{cc}
-0,3 & 0 \\
0 & -0,25
\end{array}\right]
$$

Untuk keperluan simulasi, transisi mode dalam sistem diperlihatkan pada gambar 6 dan hasil simulasi lingkar tertutupnya diberikan dalam gambar 7. Terlihat bahwa pengendali yang dirancang berhasil membuat sistem keseluruhan menjadi stabil.

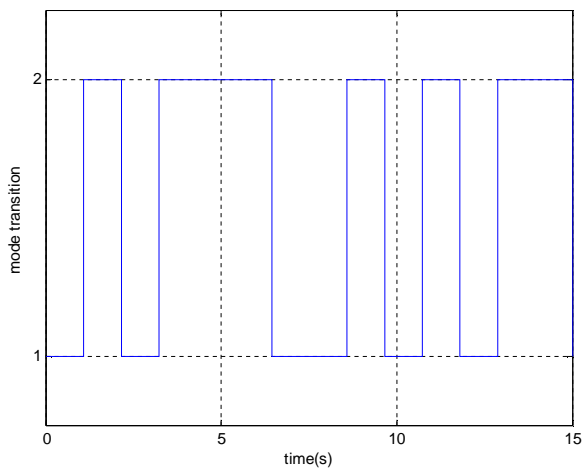

Gambar 6. Transisi mode 


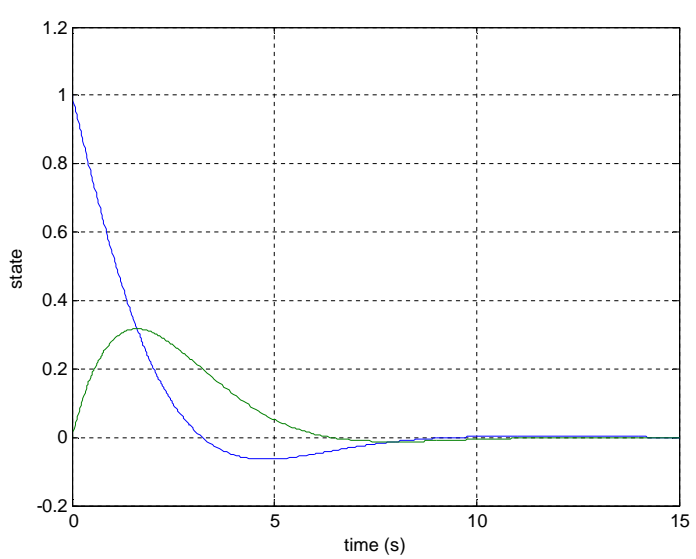

Gambar 7. Respon lingkar tertutup

\section{KESIMPULAN}

Dalam makalah, pemodelan dan perancangan pengendali untuk Networked Control Systems dengan pendekatan Markovian Jump Systems telah diuraikan. Pengendali yang dirancang menggunakan umpan balik keadaan sistem. Untuk menjamin kinerja sistem yang diinginkan, pengendali memerlukan data keadaan yang diperoleh dari sensor dan informasi tentang parameter jaringan. Formulasi perancangan pengendali menggunakan skema pertidaksamaan matriks linier. Hasil simulasi memperlihatkan pengendali yang dirancang mampu menghasilkan kinerja sistem lingkar tertutup sesuai yang diinginkan. Penelitian berikutnya yang sedang dilakukan adalah menerapkan konsep kendali kokoh (robust control) yang menjamin kestabilan sistem dan pencapaian kinerja yang diinginkan apabila terdapat gangguan yang masuk ke dalam sistem atau adanya ketidakpastian parameter yang muncul dalam sistem.

\section{DAFTAR PUSTAKA}

[1] R. A. Gupta \& M. Y. Chow, "Networked Control Systems : Overview and Research Trends", IEEE Trans. on Industrial Electronics, vol. 57, no. 7, pp. 2527 - 2535, July 2010.

[2] W. Zhang, et al, "Stability of Neworked Control Systems", IEEE Control Systems Magazine, vol. 21, no. 1, pp. 84 - 99, 2001.

[3] D. H. Varsakelis \& W. S. Levine (eds), "Handbook of Networked and Embedded Control Systems", Birkhauser Boston, 2005.

[4] W. P. M. H. Heemels, et al, "Networked Control Systems with Communication Constraints: Tradeoffs between Transmission Intervals, Delays and Performance", IEEE Trans. on Automatic Control, vol. 55, no. 8, pp. 1781 - 1796, August 2010.

[5] W. P. M. H. Heemels \& N. van de Wouw, "Stability and Stabilization of Networked Control Systems" in A. Bemporad, et al (eds), "Networked Control Systems", Springer-Verlag Berlin Heidelberg, 2010, pp. $203-253$.

[6] A. Najmurrokhman, dkk., "Output Feedback Controller for Dissipative Networked Control Systems via Markovian Jump System Approach", Proc. International Conf. on Intelligent Unmanned Systems, 3 - 4 Nov. 2010, Bali, Indonesia.

[7] D. Huang \& S. K. Nguang, "Robust Control for Uncertain Networked Control Systems with Random Delays”, Springer-Verlag Berlin Heidelberg, 2009, halaman 17.

[8] W. Ridwan and B. Riyanto, " $\mathrm{H}_{\infty}$ control synthesis for Networked Control Systems with Time Delay System Approach", Proc. International Conf. on Electr. Eng. and Informatics, 17 - 19 July 2011, ITB, Bandung.

[9] H. Ishii, " $\mathrm{H}_{\infty}$ control with limited communication and message losses", Systems \& Control Letters (57), pp. $322-331,2008$.

[10] O. L. V. Costa, et al, "Discrete-time Markov Jump Linear Systems", Springer-Verlag London, 2005. 
[11] M. D. S. Aliyu \& E. K. Boukas, "Robust H-infinity Control for Markovian Jump Nonlinear Systems ”, Journal of Mathematical Control and Information, Vol. 17, pp. 295 - 308, 2000.

[12] E. K. Boukas, "Stochastic Switching Systems", Birkhauser Boston, 2006, halaman 72.

[13] P. Gahinet, et al, "LMI Control Toolbox", The Mathworks Inc., 1995.

[14] S. Boyd, et al, "Linear Matrix Inequalities in Systems and Control Theory", SIAM Books, Philadelphia, 1994. 